\title{
Una élite regional en la Monarquía de Alfonso XIII: la clase política de Cantabria
}

\author{
Aurora Garrido Martín *
}

A lo largo de estas páginas pretendemos dejar constancia de los que fueron los rasgos característicos de la clase política de Cantabria representada en las Cámaras nacionales durante la etapa parlamentaria del reinado de Alfonso XIII, así como su relevancia en el marco de la élite nacional y su función dentro del sistema político de la Restauración en general. Si hubiera que señalar un primer rasgo que definió a los diputados y senadores por Cantabria, no sólo durante el primer tercio del actual siglo sino a lo largo de toda la Restauración, éste sería su casi absoluta identificación política con la élite gobernante a nivel nacional. Cantabria constituyó, en este sentido, un área de dominio del partido conservador, que acaparó el $52 \%$ de la representación regional en el Congreso de los Diputados y cuya presencia fue también predominante en el Senado. En líneas generales, en Cantabria se produjo una perfecta «entente» entre las organizaciones regionales de los partidos del turno para el reparto de las actas de la región; dentro de las cuales el predominio conservador respondía a la mayor pujanza de la organización conservadora en el contexto de la política regional, cuya dirección ostentó durante esos años. Cantabria de 1902 a 1923 sólo contó con un diputado -el católico integrista Marcial Solana, que obstentó su representación durante la legislatura de 1916 a 1918- y con dos senadores -el maurista conde de Limpias, elegido en 1919, y el reformista Luis Hoyos Sainz, en 1923-. Este casi monopolio de los puestos regionales en am-

\footnotetext{
* Universidad de Cantabria.
} 
bas Cámaras por parte de conservadores y liberales denota, consiguientemente, la gran adaptación de la región, en general, al sistema político de la Restauración.

La élite política de Cantabria fue una élite básicamente autóctona; natural $u$ originaria de la región, en la que conservaba propiedades y parentela, y si no, con fuertes intereses económicos que defender en ella. Este fue el caso del industrial y naviero vasco Luis Aznar -único político no oriundo de Cantabria-, gerente de una de las mayores compañías mineras de la región, la Compañía de Setares. Situada ésta en el municipio de Castro Urdiales, el de mayor entidad del distrito electoral de Castro-Laredo por el que Aznar fue diputado de 1910 a 1923, año en que pasó al Senado. Cantabria no fue, pues, una tierra abonada para "cuneros", para políticos advenedizos que pretendieran utilizar la región como trampolín político. No obstante, se trató también, en su mayor parte, de una élite no residente en Cantabria sino en la capital de la nación. A la Montaña la mantenían vinculada un patrimonio, mayor o menor según los casos, unos lazos familiares y unas estancias, religiosamente mantenidas, durante los períodos estivales. En cualquier caso -y ello es lo verdaderamente importante - fue una élite que contó con el beneplácito de las fuerzas sociales y políticas predominantes en la región - sin el que, por otra parte, era impensable pasar a formar parte de ella-; las cuales, si bien estaban imposibilitadas, por su debilidad, para jugar un papel relevante a nivel nacional, preservaron el espacio regional como una zona de exclusiva hegemonía.

La clase política de Cantabria presentó también un alto grado de estabilidad dentro de las agrupaciones políticas. No fue, pues, el transfugismo, por otro lado tan ligado a la fisonomía de los partidos del turno, un rasgo de la misma; lo que hace referencia a la fuerte consolidación de las influencias políticas en el interior de la región, de tal manera que no podían verse sustancialmente alteradas por el trasvase de una formación a otra con el fin de sacar provecho político de los cambios en la dirección de la política nacional ${ }^{1}$. Tuvieron los diputados y senadores de

${ }^{1}$ Los casos de José María de la Viesca, marqués de Viesca, y de Justo Sarabia y Pardo, marqués de Hazas, los dos ejernplos más significativos -y los únicos- del transfugismo político en este período que tratamos, resultan ilustrativos al respecto. Ambos políticos, tras elecciones legislativas de 1903 , el primero debido a que había dejado de ser el líder incuestionable del partido conservador, y el segundo porque el mismo partido había desatendido su pretensión de ser diputado por la región, pasaron a engrosar las filas del partido liberal. Sin embargo, ello no evitó el declive progresivo, hasta su completa desaparición de la política regional, del marqués de Viesca por su pérdida de influencia; ni fue 
Cantabria una cierta continuidad y permanencia en sus cargos. Algo esencial, según apuntó Linz, "para que se creen entre los miembros de la clase política vínculos personales, relaciones de amistad y respeto mutuo, muchas veces superando diferencias ideológicas y de partido que facilitan la colaboración en el proceso legislativo, contactos y soluciones de crisis» ${ }^{2}$. En el caso de Cantabria, dicha continuidad es perfectamente constatable si se tiene en cuenta que de 1902 a 1923 dieciocho políticos acapararon las cincuenta actas al Congreso por la región y que el $22 \%$ de los Diputados obtuvieron el $50 \%$ de las mismas. Esta tendencia a la acaparación de cargos es sólo ligeramente menos acusada en el Senado, donde casi un $58 \%$ de los senadores no repitieron legislatura. Se da también la circunstancia de que al menos la mitad de los senadores habían pasado previamente por el Congreso o lo hicieron -en casos excepcionales, mientras esperaban un puesto de diputado- después. Muchos de estos políticos, el $45 \%$, aproximadamente, de los diputados y senadores, habían formado parte - ellos mismos o sus más inmediatos ascendientes - de la élite política de Cantabria a lo largo de toda la Restauración. Eran los representantes de las "familias políticas» de la región, algunas de las cuales se remontaban a la época moderada. Nos estamos refiriendo a los Viesca, García Lomas, Alvear, Fernández Hontoria, Garnica o López: Dóriga.

Algunos miembros de la élite política habían iniciado su carrera en la administración provincial o municipal, si bien la mayoría de ellos accedió directamente al Congreso o al Senado. Fueron éstos los que procedían de las familias políticas de Cantabria o potentados económicos. Se estableció, así, una cierta disociación entre los representantes de Cantabria en las Cortes y los políticos que desarrollaron su actividad pública en la Diputación Provincial o en el Municipio. Existían, en este sentido dos élites diferentes: una a nivel nacional, residente generalmente en Madrid, segunda o tercera generación de políticos, que no precisaba pasar por el campo de rodaje de la Diputación o la administración municipal, habitual para aquellos políticos que sin contar con el aval de una tradición y de unas influencias y apoyos heredados pretendían hacer carrera en la política, y a la que fundamentalmente le interesaba estar presente en las instituciones nacionales; y otra élite, presente en la región, sin más am-

suficiente, por lo mismo, para que el marqués de Hazas fuese diputado, a pesar de intentarlo.

${ }^{2}$ LINZ, J. J., "Continuidad y discontinuidad en la élite política española: de la Restauración al régimen actual'", en Estudios de Ciencia Política y Sociología. Homenaje al profesor Carlos Ollero, Madrid, 1972, op. cit, pág. 362. 
bición política que la de ejercer el poder dentro del espacio político regional, y cuyos miembros poseían, en términos generales, una menor cualificación.

En cuanto a su caracterización socio-profesional, y coincidiendo en tal sentido con la norma que se daba a nivel del Estado, fueron también los abogados los que predominaron dentro de la representación cántabra. Fueron abogados más del $64 \%$ de los diputados, mientras que la proporción se reduce entre los senadores aproximadamente a la mitad de los casos analizados. El resto de la élite politica aparece constituida por industriales o propietarios, especialmente por los primeros. Conviene matizar, no obstante, que un porcentaje importante de los diputados con formación jurídica - en torno al $45 \%$ de ellos- formaban parte asimismo de la élite económica de la región o pertenecian a las familias de mayor relevancia económica de la misma; aunque la gestión directa de los negocios no pareciera ser su actividad profesional preferente. Aquélla era ejercida por otro miembro del clan familiar, de acuerdo a una división que se daba con cierta frecuencia en el seno de las familias poderosas de la región, a las que se ve representadas en alguno de sus miembros no sólo en el Congreso o en el Senado sino también, lógicamente, en la Diputación Provincial. La presencia de miembros de la élite económica se ve incrementada en la representación del Senado, al no requerir el cargo de senador la dedicación que el de diputado, pudiendo compatibilizarlo mejor, por tanto, con la actividad profesional. Así, a los nombres de industriales de la región que aparecen en la lista de diputados (Luis Aznar, conde de Mansilla, Francisco Albo, Gregorio Mazarrasa, José M. ${ }^{a}$ de la Viesca, Manuel García Obregón...) se suman los de otros significados hombres de negocios de la región (José María Quijano, Ramiro Pérez Eizaguirre, Santiago López, primo del marqués de Comillas, Higinio A. de Celis Cortines...). Como se ha señalado, se trata fundamentalmente de industriales, de acuerdo con la posición de preponderancia que ocupaban en estos momentos dentro de la estructura económica de la región; cuya modernización, desde finales del siglo pasado, aparecía ligada sobre todo al desarrollo industrial y al de la explotación minera. Si bien, en el caso de Cantabria, sería más apropiado referirse a una sola élite económica, ya que sus miembros participaban indistintamente en los diferentes campos de la actividad económica, también agraria, de la región. Resulta, por ello, difícil establecer una división en grupos o sectores económicos claramente diferenciados. No obstante, la definición de la élite económica derivaba, esencialmente, de su vinculación al desarrollo industrial, comercial y financiero de la región. El hecho de que no se decante en ella ningún sector dominante es consecuencia de que dentro de la modernización económica de Cantabria, desde principios de siglo, nin- 
guno se erige en protagonista e impulsor exclusivo de la misma, ninguno de ellos se destaca con especial fuerza sobre los demás. Así pues, en Cantabria, más que de grupos económicos, cabría hablar de determinadas familias como las agentes y controladoras del proceso de desarrollo económico (los Pombo, Quijano, Cortines, Alday, Abarca, Botín, Pérez Eizaguirre, López Dóriga, Huidobro, González del Camino, etc.).

En Cantabria, pues, se da también esa, ya contrastada para el conjunto del país, imbricación existente entre la élite política y la social. Se traduce en una cierta identidad física entre ambas amén de política, pues es también el grupo humano socialmente más poderoso el que engrosa sustancialmente las filas de los dos partidos dinásticos en la región. En dicho sentido, el trasvase que se produce en estos años de significados hombres de negocios (Quijano, Mazarrasa, Pombo...) hacia las organizaciones políticas de católicos y mauristas ha de interpretarse, sobre todo en el caso de los mauristas, no tanto como una desafección con el sistema de la Restauración sino como una cuestión de lealtades personales. Esta interpenetración entre ambas élites se refuerza con el establecimiento de lazos de parentesco vía matrimonio. La misma endogamia que, por otra parte, caracterizaba a la élite económica de la región estrechaba más aún los vínculos existentes entre las familias social y políticamente dominantes, limitando en mayor medida las dimensiones del sector social hegemónico en la región.

Recapitulando, a pesar de ser muy fuertes las conexiones entre los diputados y senadores con el grupo socialmente dominante en Cantabria, en sentido estricto, aquellos políticos con una presencia directa en la economía de la región representan la minoria dentro de la élite política con presencia en las Cámaras del reino. La gestión directa de sus negocios, característico de los capitalistas cántabros, —amén del desinterés personal que algunos podían sentir hacia la intervención en política- se hacía incompatible con una presencia masiva de los mismos en el ámbito de la política nacional. Por contra, son minoría los casos dentro de la élite política de Cantabria sin ningún tipo de vínculo con la élite económica regional; que, de esta forma directa o indirectamente, aparecía, en ella, representada en su mayor parte ${ }^{3}$.

\footnotetext{
${ }^{3}$ La relación siguiente recoge los políticos que de 1902 hasta 1923 fueron diputados por Cantabria, su profesión y su vinculación con la economía o la élite económica de la región:

- Pedro Acha Pérez, abogado.
} 
Además de su vinculación notable, ya fuera física o de parentesco, con las familias más pudientes, lógica, por otra parte, en el marco de una sociedad provinciana, elitista y selectiva, como era la de la Cantabria de la Restauración, estaba la presión y la influencia ejercida "desde fuera" sobre la clase política regional. Diputados y senadores se convirtieron, de esta manera, amén de, en los agentes de los caciques rurales o gestores de obras públicas para los pueblos de la región, especialmente en períodos electorales -entre tanto esta faceta de su actividad aparecía bastante ensombrecida a tenor de lo reflejado en el Diario de Sesiones del Congreso y en la prensa-, en los intermediarios y defensores permanentes de los intereses - cualquiera que fuera la naturaleza de aquéllos- del sector económicamente dominante de Cantabria ante

- Francisco Albo Kay, industrial conservero santoñés, con empresas en la localidad cántabra de Santoña.

- Emilio Alvear y Pedraja, abogado, cuyos apellidos nos remiten a dos de las familias acaudaladas de la región.

- Luis Aznar, industrial, socio-gerente de la Compañía minera de Setares (Castro Urdiales), de las más importantes que trabajaban en la región.

- Joaquín Campuzano Avilés (conde de Mansilla), abogado, consejero, entre otras empresas, de la mayor industria siderúrgica de la región, Nueva Montaña, del Ferrocarril El Cantábrico y dueño de los Baños Las Caldas de Besaya.

- Gregorio Eguilior Llaguno, propietario, hermano del que fue ministro de Hacienda y de Instrucción Pública, Manuel Eguilior.

- Ramón Fernández Hontoria (conde de Torreanaz), abogado, emparentado con familias de gran peso en la economía regional, como los Quijano, del Campo y Alday.

- Luis Fernández Hontoria y Uhagón, abogado, hijo del anterior e hijo político de Emilio Botín y López, uno de los comerciantes, industriales y banqueros más notables de Cantabria y miembro de una de las familias también más sobresalientes del capitalismo regional, hasta nuestros días propietaria del Banco de Santander.

- Juan García Lomas, abogado.

- Manuel García Obregón, abogado, consejero del Ferrocarril de Astillero a Ontaneda y de la Sociedad Minas de Heras. Emparentado con la familia Botín y González del Camino. - Pablo Garnica Echevarría, abogado. Le unían vínculos familiares con los Illera y los Pombo.

- Gregorio Mazarrasa Pardo, abogado, poseedor de uno de los apellidos más ligados al desarrollo industrial y minero de la región desde finales del siglo pasado.

- J. Manuel Mitjans Manzanedo, duque de Santoña, propietario.

- Enrique Pico Martínez, abogado.

- Luis Redonet y López Dóriga, abogado. Consejero de la más importante empresa metalúrgica de Santander, la Sociedad Talleres San Martín. También de una de las familias de negocios destacadas de Cantabria, los López Dóriga.

- Juan José Ruano de la Sota, abogado.

- Marcial Solana y González del Camino, propietario. Los González del Camino están presentes en todos los sectores de la economía cántabra.

- José María de la Viesca y Roiz, (marqués de Viesca), propietario de la industria textil La Montañesa, sita en la localidad cántabra de La Cavada. Perteneciente a la familia de los Roiz de la Parra, vinculada también al capitalismo regional y emparentado también con José Luis Gallo y Díez Bustamante de distinguida familia montañesa. 
la administración central, que, no obstante, en ocasiones podian coincidir con los de la región en general. Basta sólo con repasar la documentación de la Cámara de Comercio, Industria y Navegación de Santander para comprobar lo anterior ${ }^{4}$. En este sentido, era preceptivo que los nuevos representantes de la región en las Cortes, inmediatamente después de jurar su cargo, ofrecieran sus servicios incondicionales a la institución económica referida ${ }^{5}$.

Existió también, en la clase política, unanimidad en la defensa de los intereses de la región y/o de sus fuerzas vivas a nivel del Estado, no proyectándose en su actuación las divergencias políticas de partido. La misma unidad de acción y cohesión interna que caracterizó a los miembros de la Diputación Provincial; quienes ante la necesidad de administrar la entonces provincia de Santander marginaban las cuestiones políticas, siendo muy escasos los enfrentamientos dignos de mención que se registraron entre los partidos que integraban la Corporación provincial. Así, de la misma manera que habíamos hecho referencia a la existencia de una sola élite económica en Cantabria, puede hablarse, de hecho, de una sola y compacta élite política, en cuanto a que las diferencias de partido no se reflejaban en su actuación política, preocupada ante todo por favorecer y ayudar en lo posible a la región. Los diputados y senadores por Cantabria no desempeñaron, así, salvo casos excepcionales, un papel relevante dentro del conjunto de la élite nacional y a nivel de los grandes problemas del Estado español. La élite política de Cantabria no pasó de ser, en este sentido, una élite provinciana, "del montón», subordinada a la élite gobernante de la nación, con una vida parlamentaria discreta y preocupada, sobre todo, por los intereses regionales ${ }^{6}$. Sólo, pues, en los momentos en que vieron aquéllos compro-

${ }^{4}$ Como muestra pueden servir los siguientes acuerdos tomados en sendas sesiones de la Cámara de Santander. El 1 de julio de 1912 la Cámara acuerda «aprobar la carta que se dirige a los representantes en Cortes a fin de que no sancionen con su voto el aumento en las tarifas de la Contribución Industrial y de Comercio, que el Excmo. Sr. ministro de Hacienda propone en los presupuestos generales para el año de 1913». Mientras que en la del 8 de mayo de 1914 se acuerda "interesar a los señores senadores y diputados por la provincia gestionen sea aprobado el proyecto de Ley presentado en el Senado por el Excmo. Sr. ministro de Gracia y Justicia, en 11 de marzo de 1911, referente a las suspensiones de pagos de las Compañías o Empresas concesionarias de ferrocarriles y demás obras públicas" (Libro de Actas de la Cámara de Comercio, Industria y Navegación de Santander, vol. 4).

${ }^{5}$ Por ejemplo, en la sesión del 7 de diciembre de 1912 se da cuenta de la comunicación de $« \mathrm{D}$. Leandro Alvear diciendo, ha jurado el cargo de senador por esta provincia y ofreciendose a las órdenes de la Corporación". O en la del 22 de junio de 1923, en la que "dada cuenta de la carta recibida del Sr. Hoyos Sainz ofreciéndose a la Cámara como senador por la provincia, se acordó significarle el agradecimiento de la Corporación" (lbidem).

- De los representantes de Cantabria en las Cortes durante el período que tratamos, 
metidos reclamaron su papel en la toma de decisiones a nivel nacional. Ello coincidió con las ocasiones en las que se produjo una mayor presión sobre el poder central por parte de las instituciones políticas y económicas de la región.

Fueron, no obstante, excepcionales los temas objeto de un conflicto reseñable entre Cantabria y la Administración; algunos de los cuales constituyeron, por otra parte, reivindicaciones permanentes, con etapas de mayor o menor intensidad, desde la segunda mitad del siglo pasado, convirtiéndose dentro del marco regional en auténticas cuestiones de "Estado", de las que la opinión pública de la región y su élite económica hacian depender la plena modernización de la misma. Estas reivindicaciones, que durante muchos años constituyeron el «banderín de enganche» bajo el que se aunaron la mayor parte de los sectores sociales y políticos con cierta presencia en la vida regional, estaban estrechamente ligadas al progreso del puerto de Santander. Éste había sido pieza clave en el desarrollo del capitalismo regional, pero su pujanza, dentro del contexto nacional, derivada del control del comercio con el centro del país y de la exportación del trigo y las harinas castellanas, se había visto cuestionada desde el último cuarto de la pasada centuria por la competencia de los puertos vascos y asturianos a causa de las altas tarifas en la región de la Compañia de Ferrocarriles del Norte. Surgió, así, la idea del Ferrocarril del Meridiano, directo de Santander a Madrid por Burgos en el que las fuerzas vivas de Cantabria pondrían grandes esperanzas para dar término a los excesos de la Compañía del Norte. Este proyecto se transformaría después en el más ambicioso del Ferrocarril del Mediterráneo o Ferrocarril Santander-Burgos-Soria-Calatayud. El otro gran problema del desarrollo regional era el propio puerto, sus mejoras técnicas y, sobre todo, la construcción de un depósito o puerto franco. Estos fueron los principales "caballos de batalla" de la región y de su élite política, también, frente al poder central. El depósito franco fue concedido en 1921 y el proyecto del Ferrocarril del Mediterráneo fue aprobado durante la dictadura de Primo de Rivera, si bien nunca llegó a construirse.

ocuparon direcciones Generales Juan José Ruano de la Sota, de Obras Públicas en 1917 y de Comunicaciones en 1919 y Pablo Garnica Echevarría, de lo Contencioso en 1910 y de Contribuciones en 1917. Fueron subsecretarios Ramón Fernández Hontoria (conde de Torreanaz), de Gobernación en 1902 y de la Presidencia en 1905; Enrique Pico, de Gobernación en 1918; Pablo Garnica, de Hacienda en 1917 y Juan José Ruano, de Gobernación en 1920. Ministros, Manuel Eguilior (conde de Albox), fugaz ministro de Hacienda (15-XI1902 a 5-XI1-1902) y de Instrucción Pública (veinticuatro horas) en 1905; Pablo Garnica, de Abastecimientos en 1918 y de Gracia y Justicia en 1919 y Juan J. Ruano, también fugaz ministro de Hacienda (3-XII-1922 a 7-XII-1923). 